\title{
Monoxide Ion Signals in Inductively Coupled Plasma Mass Spectrometry
}

\author{
Masaaki Kubota, Noriko Fudagawa and Akira Kawase \\ National Chemical Laboratory for Industry, Higashi, Tsukuba, Ibaraki 305, Japan
}

\begin{abstract}
The ion signals of oxide-forming elements $\left(\mathrm{M}^{+}\right)$and their monoxides $\left(\mathrm{MO}^{+}\right)$have been investigated as functions of inductively coupled plasma operating parameters. An appropriate selection of the radio frequency power, carrier-gas flow rate and sampling depth was essential in order to minimize the signal ratio, $S_{\mathrm{MO}(+)} / S_{\mathrm{M}(+)^{+}}$. Signals $S_{\mathrm{MO}_{(+)}}$and $S_{\left.\mathrm{M}_{(+)}\right)}$decreased drastically with increasing radial distance from the plasma center. The signal ratios $S_{\mathrm{MO}(+)} / S_{\left.\mathrm{MS}_{+}\right)}$for various analytes, in consideration of partition functions and mass numbers, showed a linear relation with the oxide dissociation energies. Equivalent concentration data are also given for typical oxide interferences.
\end{abstract}

Keywords Inductively coupled plasma mass spectrometry, monoxide ion signals, spectral interferences

Since the first publication on inductively coupled plasma mass spectrometry (ICP-MS) in $1980^{1}$, this method has shown rapid development as a new technique for trace elemental and isotopic analyses. ${ }^{2-7}$ The simplicity of the spectra as well as the high sensitivity are advantages of this technique over ICPatomic emission spectrometry. In ICP-MS, however, it has been noted that serious spectral interference can occur due to doubly-charged ions and/or poly-atomic ions, particularly from matrix elements present at higher concentrations than an analyte. ${ }^{8,9}$ Horlick and co-workers carried out extensive studies of the effects of plasma operating parameters on the signals, not only of singly-charged analyte ions $\left(\mathrm{M}^{+}\right)$but of monoxide ions $\left(\mathrm{MO}^{+}\right)$, hydroxide ions $\left(\mathrm{MOH}^{+}\right)$and doublycharged ions $\left(\mathrm{M}^{2+}\right)$. $^{8,10}$ They presented a pair of tables indicating the potential spectral interferences caused by $\mathrm{MO}^{+}, \mathrm{MOH}^{+}$and $\mathrm{M}^{2+}$ species. Although the behavior of signals changing with the plasma operating parameters have also been reported in many other papers ${ }^{1-15}$, the indication by Horlick $e$ al.$^{10}$ that more results concerning the behavior are needed from other laboratories and instruments is still felt to be reasonable for any essential understanding of the characteristics of ICP-MS.

The present paper focuses on the signals of monoxide ions of elements since, in general, fewer elements form detectable hydroxide and doubly-charged ions than those that form oxide ions. The influence of various critical operating parameters on the signals of oxides and the signal ratios of oxide to singly-charged ions $\left(S_{\mathrm{MO}(+)} / S_{\mathrm{M}(+)}\right)$ is presented. The parameters included the carrier-gas flow rate, applied radio frequency $(\mathrm{rf})$ power, sampling depth and radial position from the plasma central axis. The variation of $S_{\mathrm{MO}(+)} / S_{\mathrm{M}(+)}$ with the dissociation energy of the oxide for a variety of oxide-forming elements is also discussed.

\section{Experimental}

The ICP-MS instrument employed was a Seiko Model SPQ-6100S (Seiko Instruments Inc., Tokyo, Japan). The main components of the instrumentation and the typical operating conditions are given in Table 1. Under the operating conditions a ${ }^{204} \mathrm{~Pb}$ signal with $1 \mathrm{ng} \mathrm{ml}^{-1}$ could be satisfactorily separated from the ${ }^{203} \mathrm{Tl}$ and ${ }^{205} \mathrm{Tl}$ peaks with $1 \mu \mathrm{g} \mathrm{ml}^{-1}$, and the signal response of cobalt, barium and lead was $1 \times 10^{5}-5 \times 10^{5}$ counts $\mathrm{s}^{-1}$ per $100 \mathrm{ng} \mathrm{ml}^{-1}$.

Commercially available metal standard solutions

Table 1 Instrumentation and typical operating conditions

Plasma generator Frequency $27.12 \mathrm{MHz}$, input power $1.2 \mathrm{~kW}$ (Max. $2 \mathrm{~kW})$

Nebulizer Glass concentric with spray chamber

Argon flow rate Plasma 15 , auxiliary 1.1 , carrier 1.0 $1 \mathrm{~min}^{-1}$

Mass spectrometer Q-pole rod diameter $9.5 \mathrm{~mm}$, rod length $20 \mathrm{~cm}$, rf frequency $3.0 \mathrm{M} \mathrm{Hz}$

Sampling depth $\quad 5 \mathrm{~mm}$ from top of load coil

Sampling cone Copper $120^{\circ}$ cone, oriffice diameter $1.1 \mathrm{~mm}$

Skimmer cone Copper $60^{\circ}$ cone, oriffice diameter $0.6 \mathrm{~mm}$

Vacuum system 1st stage $1.5,2$ nd stage $4 \times 10^{-5}, 3$ rd stage $1 \times 10^{-6}$ Torr

Ion lens setting Optimized for ${ }^{59} \mathrm{Co},{ }^{138} \mathrm{Ba}$ and ${ }^{208} \mathrm{~Pb}$

Detector Channeltron (Galireo 4816), applied voltage $2.6 \mathrm{kV}$

Signal measurement Dwell time $10 \mathrm{~ms}$, accumulation 20 
were used. The solutions were diluted appropriately with ion-exchanged distilled water just before use.

\section{Results and Discussion}

\section{Singly charged ion and monoxide ion signals}

The effects of the carrier-gas flow rate and the rf power on the signals of oxide-forming elements and their monoxide ions were investigated. The result concerning cerium is given in Fig. 1 as an example of the behavior of the signals observed with our instrument, though similar experimental results have been reported in the literature. ${ }^{8,10-14} \mathrm{The}^{\mathrm{Ce}}{ }^{+}$and $\mathrm{CeO}^{+}$ions showed a rather complicated behavior with the carriergas flow rate. The occurrence of the maximum and secondary peaks within the range of the gas-flow rate studied can also be seen for $\mathrm{Ce}^{+}$in a paper of Longerich et al. ${ }^{12}$ In Fig. 1, as the rf power increases the gas-flow rate at which the signal is maximized seems to increase. With an rf power of $0.9 \mathrm{~kW}$, the fraction of $\mathrm{CeO}^{+}$, i.e., the ratio $\mathrm{CeO}^{+} / \mathrm{Ce}^{+}$, increases rapidly at a gas-flow rate of $1.01 \mathrm{~min}^{-1}$. At a gas-flow rate range lower than $0.951 \mathrm{~min}^{-1}$ there is no significant difference in the fraction at different $\mathrm{rf}$ powers and the gas-flow rates.

The sampling position of the plasma also affects both singly-charged ion and oxide-ion signals. The effect of the sampling depth $(3-15 \mathrm{~mm})$ with $\mathrm{rf}$ powers of 0.9 , 1.2 and $1.5 \mathrm{~kW}$ is illustrated in Fig. 2 for cerium and in Fig. 3 for barium. The ionization potential of $\mathrm{Ce}$ $(5.47 \mathrm{eV})$ is nearly equal to that of $\mathrm{Ba}(5.2 \mathrm{eV})$, though the dissociation energy of $\mathrm{CeO}(7.82 \mathrm{eV})$ is higher than that of $\mathrm{BaO}(5.96 \mathrm{eV})$. At a given sampling depth larger than $5 \mathrm{~mm}$, the intensities of the $\mathrm{Ce}^{+}$and $\mathrm{CeO}^{+}$ions increase with increasing rf power, and reach a maximum at around $5 \mathrm{~mm}$. They then decrease with increasing sampling depth, though the varying rate with the sampling depth is more rapid for the $\mathrm{CeO}^{+}$ion than for the $\mathrm{Ce}^{+}$ion. A similar tendency has been seen for the $\mathrm{BaO}^{+}$and $\mathrm{Ba}^{+}$ions. The values of $\mathrm{CeO}^{+} / \mathrm{Ce}^{+}$and $\mathrm{BaO}^{+} / \mathrm{Ba}^{+}$reach a maximum at a sampling depth of $4 \mathrm{~mm}$ and show either a decrease, or a decrease followed by an increase, as the sampling depth increases. It should be noted that at a given sampling depth the ratio $\mathrm{BaO}^{+} / \mathrm{Ba}^{+}$shows smaller values with larger rf powers, but the ratio $\mathrm{CeO}^{+} / \mathrm{Ce}^{+}$has the opposite sort of trend. In most papers ${ }^{8,10,13,14}$ the ratio $\mathrm{MO}^{+} / \mathbf{M}^{+}$shows a decreasing behavior with an increasing if power. However, the opposite trend was also reported: for example, for $\mathrm{WO}^{+} / \mathrm{W}^{+}$with a $\mathrm{VG}$ instrument (England). ${ }^{14}$

Under the experimental conditions used in this study, the value of $\mathrm{CeO}^{+} / \mathrm{Ce}^{+}$was larger than that of

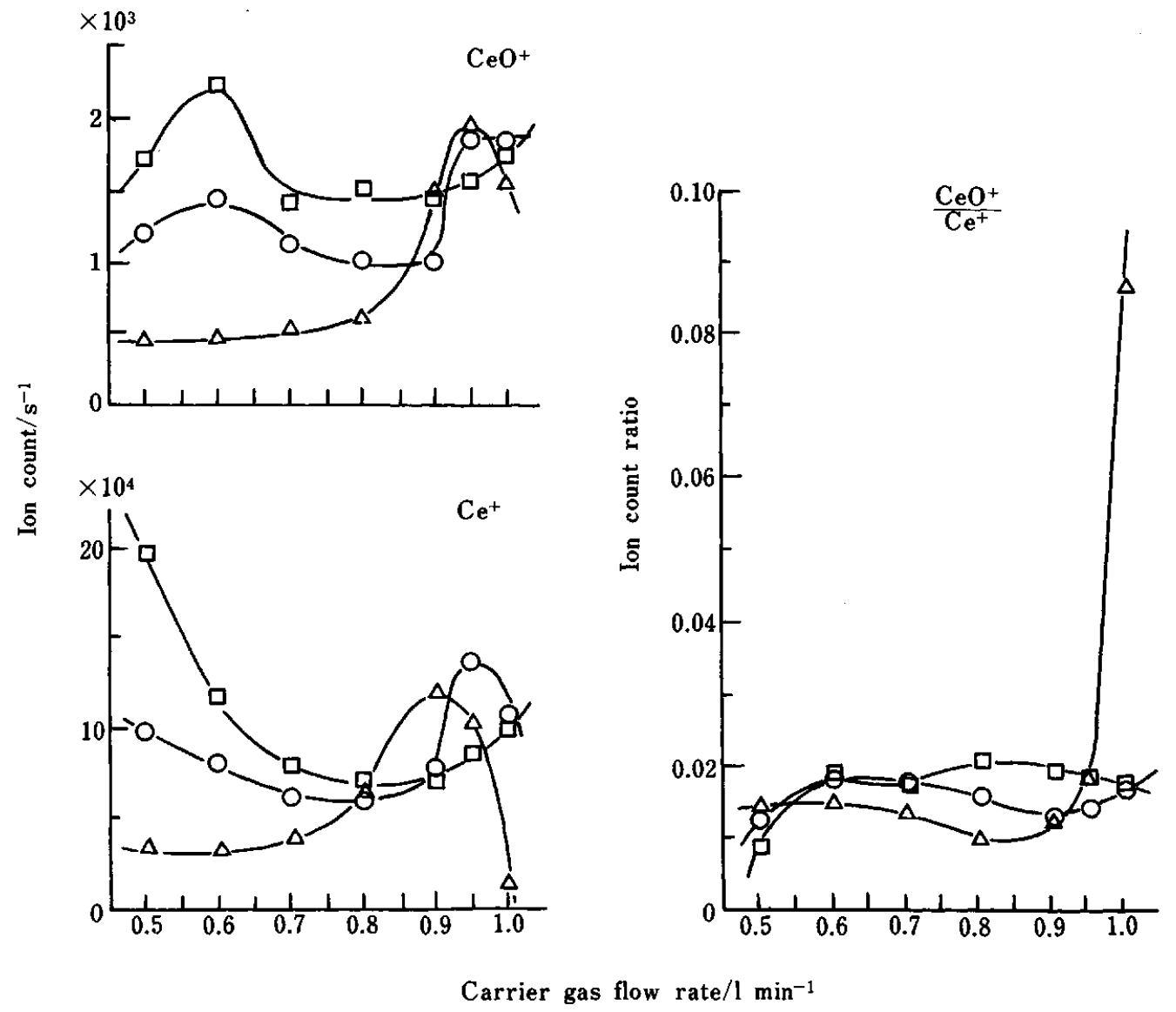

Fig. 1 Dependence of the signals of $\mathrm{Ce}^{+}$and $\mathrm{CeO}^{+}$ions and their ratio on the carrier gas flow rate at various rf powers. $\Delta, 0.9 \mathrm{~kW} ; 0,1.2 \mathrm{~kW} ; \square, 1.5 \mathrm{~kW}$. 


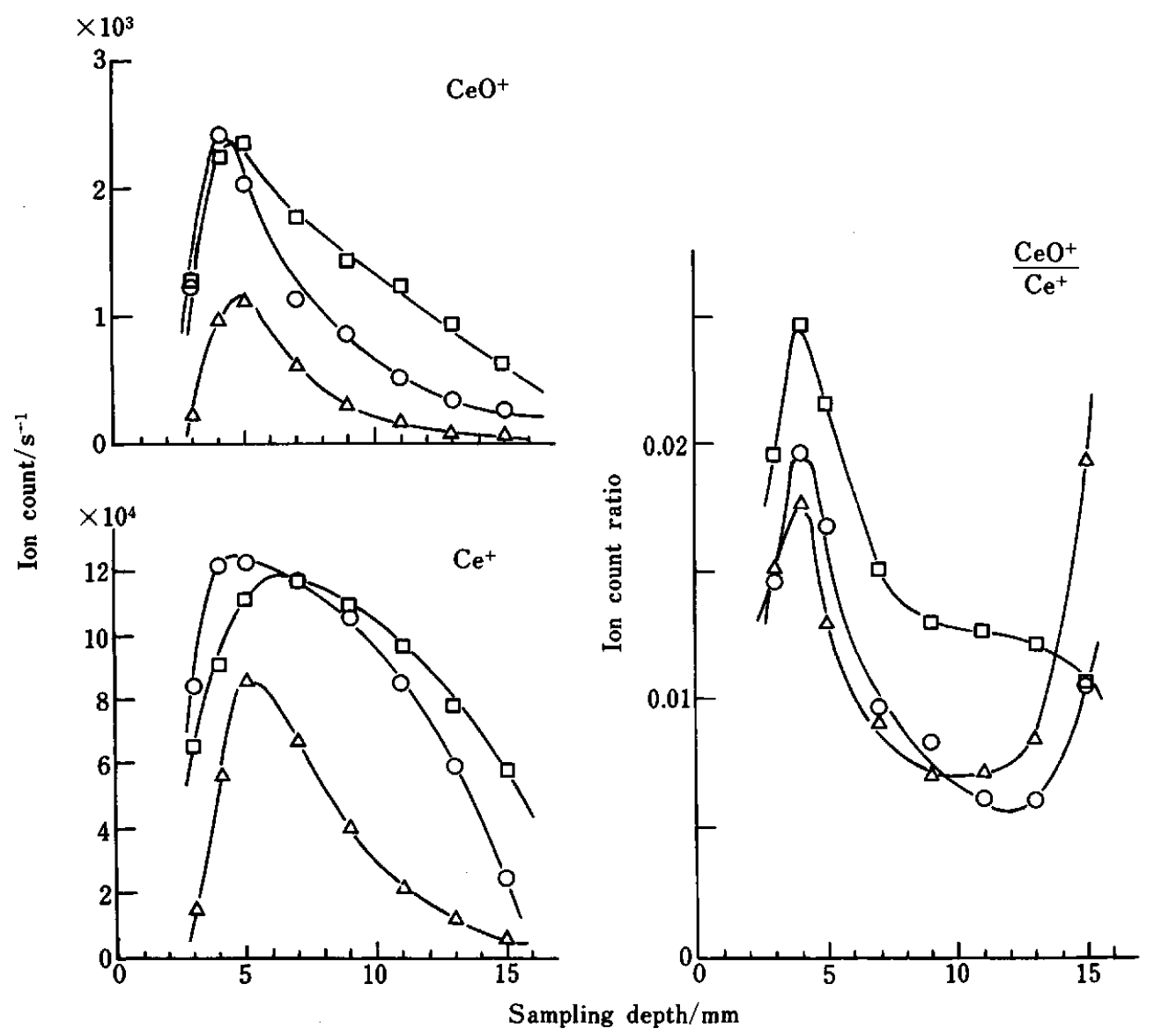

Fig. 2 Dependence of the signals of $\mathrm{Ce}^{+}$and $\mathrm{CeO}^{+}$ions and their ratio on the sampling depth at various rf powers. Symbols: see Fig. 1.

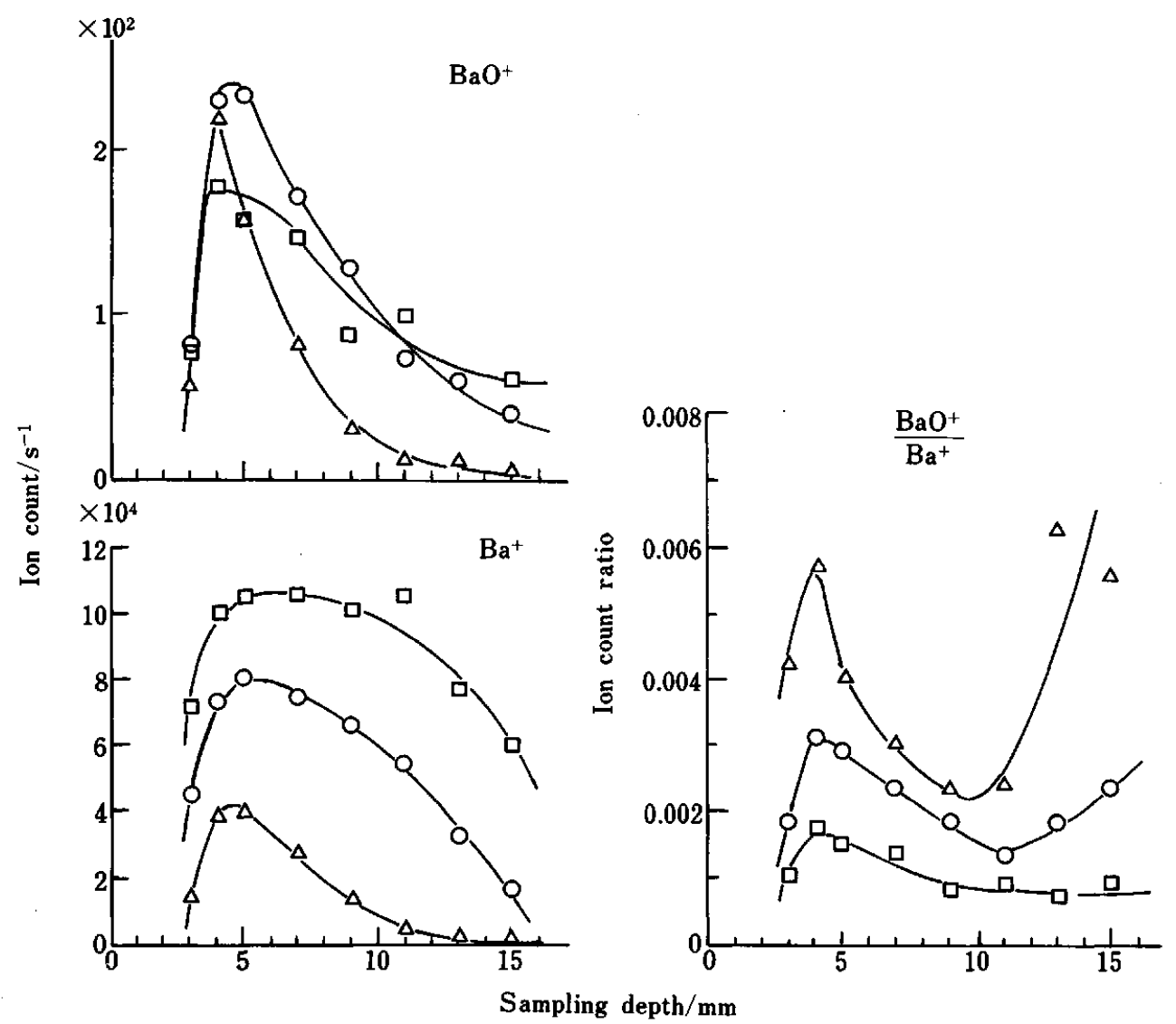

Fig. 3 Dependence of the signals of $\mathrm{Ba}^{+}$and $\mathrm{BaO}^{+}$ions and their ratio on the sampling depth at various rf powers. Symbols: see Fig. I. 
$\mathrm{BaO}^{+} / \mathrm{Ba}^{+}$, probably due to higher dissociation energy of $\mathrm{CeO}$ than that of $\mathrm{BaO}$. In order to reduce the formation of such oxide ions, it is clear that a sampling depth of around $10 \mathrm{~mm}$ must be selected. Under the conditions (rf power, $1.2 \mathrm{~kW}$; carrier-gas flow rate, $0.91 \mathrm{~min}^{-1}$; sampling depth, $10 \mathrm{~mm}$ ) which can nearly minimize oxide formation, the value of $\mathrm{CeO}^{+} / \mathrm{Ce}^{+}$was 0.006 , lower than the reported values (approximately $\left.0.8^{12}, 0.03^{17}, 0.013^{18,19}\right)$. The value $(0.0018)$ obtained for $\mathrm{BaO}^{+} / \mathrm{Ba}^{+}$was also lower than some literature values $\left(0.02-0.18^{8}\right.$, approximately $\left.0.01^{12}\right)$, but higher than the value $\left(8.3 \times 10^{-4}\right)$ reported by Gray et al. ${ }^{18}$ who took great care to minimize the formation of oxides by ionmolecule reactions within the expansion stage.

With the instrument used in this study, the support-

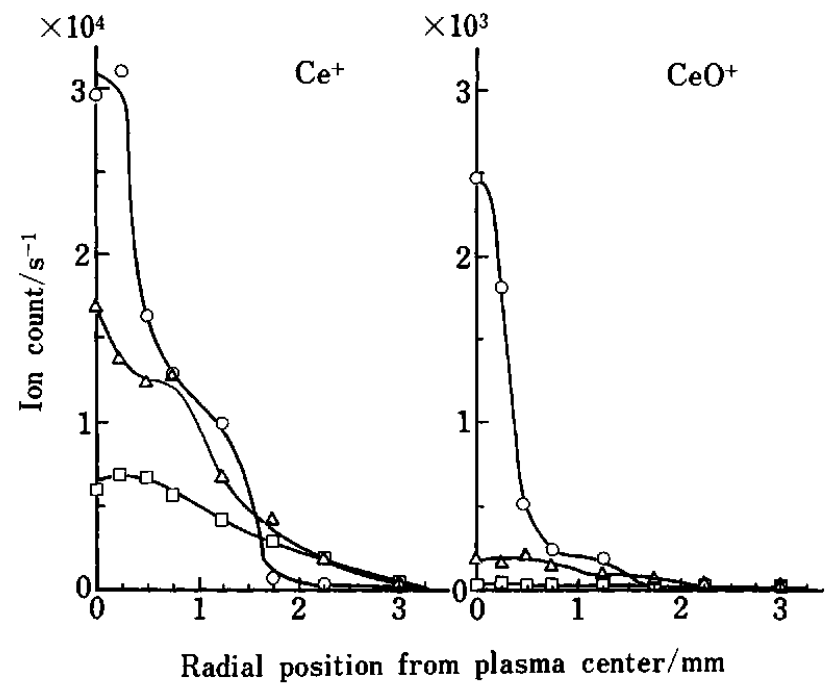

Fig. 4 Radial signal distributions of $\mathrm{Ce}^{+}$and $\mathrm{CeO}^{+}$ions at various sampling depths. $O, 5 \mathrm{~mm} ; \Delta, 8 \mathrm{~mm} ; \square, 12 \mathrm{~mm}$.

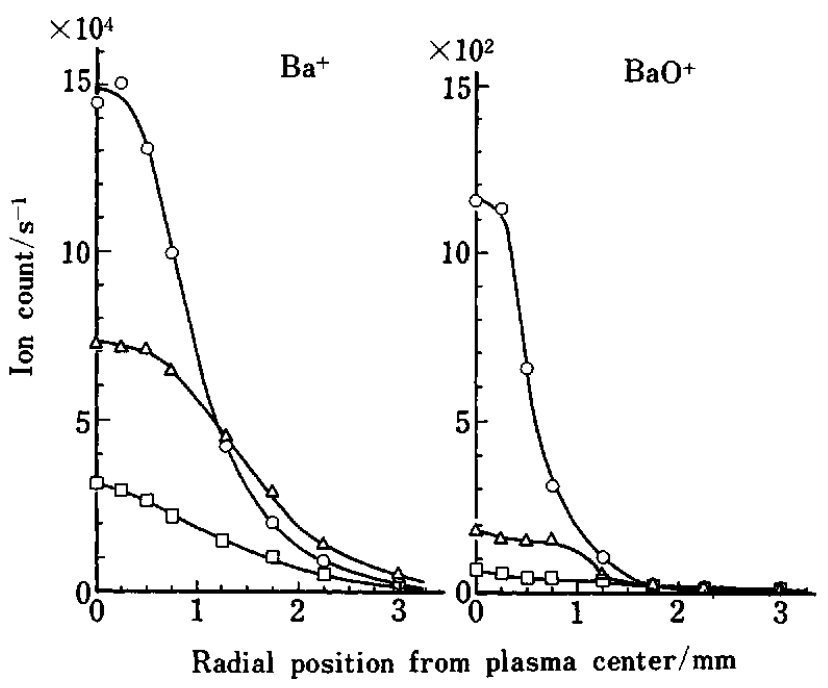

Fig. 5 Radial signal distributions of $\mathrm{Ba}^{+}$and $\mathrm{BaO}^{+}$ions at various sampling depths. Symbols: see Fig. 4. ing stage of the plasma torch could be moved in a rightangled direction as well as in a direction parallel to the plasma central axis. Thus, the radial distribution of the intensity of ions was measured by changing the distance from the plasma center from 0 to $3 \mathrm{~mm}$. The results are given in Fig. 4 for $\mathrm{Ce}^{+}$and $\mathrm{CeO}^{+}$and in Fig. 5 for $\mathrm{Ba}^{+}$ and $\mathrm{BaO}^{+}$. As the distance increases, the intensity decreases, and the reduction rate is more significant at a smaller sampling depth $(5 \mathrm{~mm})$ than at larger depths $(8$ and $12 \mathrm{~mm}$ ). At a depth of $5 \mathrm{~mm}$, it is more significant for the oxide ions than for the element ions, and the most drastic drop is observed for the $\mathrm{CeO}^{+}$ion. This indicates that very refractory metals, such as cerium, generate intense oxide ion signals, particularly when ions are sampled from the initial radiation zone, i.e., the radial center of the plasma near the load coil where a lower temperature of the plasma can result in an insufficient dissociation of oxides.

\section{$S_{M O+)} / S_{M(+)} v s$. oxide dissociation energy}

The measurement of the oxide levels for various elements, mostly refractory metals, is of significance to estimate the degree of spectral interferences associated with $\mathrm{MO}^{+}$ion signals. It is also necessary for a study of the origin of oxide signals. ${ }^{17}$ As expected from the result in Fig. 1 , the use of a lower rf power $(0.9 \mathrm{~kW})$ and a higher carrier-gas flow rate $\left(1.01 \mathrm{~min}^{-1}\right)$ can lead to a larger $S_{\mathrm{MO}(+)} / S_{\mathrm{M}(+)}$. Under this oxide-forming condition, the ratios $S_{\mathrm{MO}(+)} / S_{\mathrm{M}(+)}$ were measured for 16 elements, of which oxide dissociation energies $\left(E_{\mathrm{d}}\right)^{20,21}$ ranged from 4 to $8 \mathrm{eV}$. Data are shown in Fig. 6 in which the ratios are plotted $v s$. $E_{\mathrm{d}}$ of the oxides. No oxide signal was observed for elements having an $E_{\mathrm{d}}$ below $4.4 \mathrm{eV}$, such as lead, manganese and nickel. Figure 6 indicates that the ratios occur roughly in the same order as the dissociation energies. This is in agreement with the relations between the ratio $S_{\mathrm{MO}(+) /}$

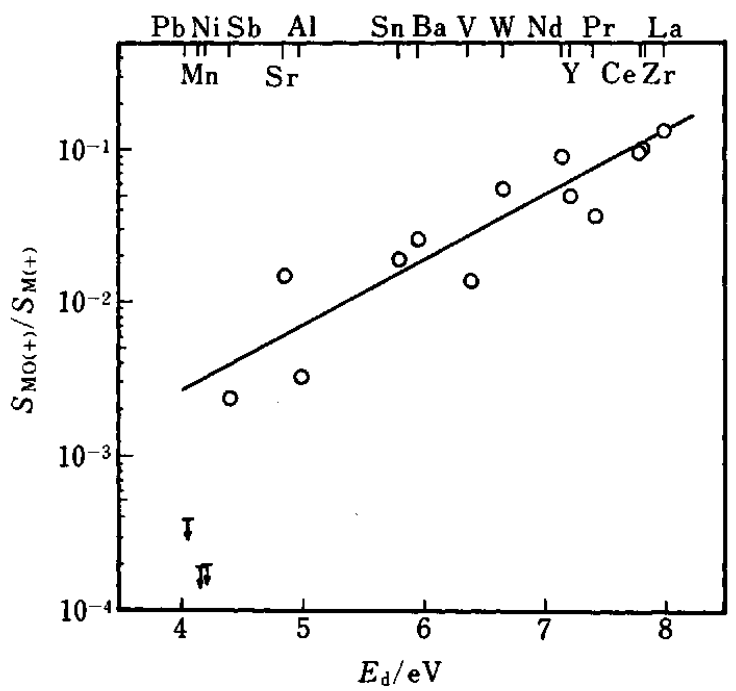

Fig. 6 Signal ratio of the oxide ion to a metal singly-charged ion as a function of the oxide dissociation energy. 
$S_{\mathrm{M}(+)}$ and the oxide bond strength $\left(D_{0}\right)$ reported for rare earth elements ${ }^{12,17}$ and 15 elements spanning a wide range of bond strengths. ${ }^{18}$ Douglas et al. ${ }^{17}$ tried to fit a temperature to the relation by assuming $S_{\mathrm{MO}(+)} / S_{\mathrm{M}(+)}$ $\propto \exp \left(D_{0} k^{-1} T^{-1}\right)$ where $k$ is the Boltzmann's constant and $T$ is the temperature. The temperature they obtained was $21000 \mathrm{~K}$. Based on a similar experiment, Longerich et al. ${ }^{12}$ reported a temperature of $10100 \mathrm{~K}$. Since the temperature by Douglas et al. was far higher than any observed ICP temperature, they concluded that the ratios $S_{\mathrm{MO}(+)} / S_{\mathrm{M}(+)}$ indicated a large departure from equilibrium and that the concept of temperature was less appropriate.

If we consider the dissociation equilibrium $\mathrm{MO} \rightleftharpoons \mathrm{M}+$ $\mathrm{O}$, the ratio of the number density of $\mathrm{MO}$ to that of $\mathrm{M}$ is given by

$$
\begin{aligned}
n_{\mathrm{MO}} / n_{\mathrm{M}}= & Z_{\mathrm{MO}} /\left(-2 \pi m_{\mathrm{M}} m_{\mathrm{O}} k T / h^{2} m_{\mathrm{MO}}\right)^{3 / 2} Z_{\mathrm{M}} Z_{\mathrm{O}} \times \\
& n_{\mathrm{O}} \exp \left(E_{\mathrm{d}} / k T\right),
\end{aligned}
$$

where $n$ is the number density, $m$ the atomic weight or the molecular weight, $Z$ the partition function, and subscripts $M, O$ and MO express a metal element, oxygen and a monoxide, respectively. For the ionization equilibriums $\mathrm{M} \rightleftharpoons \mathrm{M}^{+}+\mathrm{e}^{-}$and $\mathrm{MO} \rightleftharpoons \mathrm{MO}^{+}+$ $\mathrm{e}^{-}$, the equilibrium constants are

$$
k_{\mathrm{l}}=n_{\mathrm{M}(+)} n_{\mathrm{e}(-)} / n_{\mathrm{M}}
$$

and

$$
k_{2}=n_{\mathrm{MO}(+)} n_{\mathrm{e}(-)} / n_{\mathrm{MO}}
$$

The elimination of $n_{\mathrm{e}(-)}$ from the Eqs. (2) and (3) gives

$$
n_{\mathrm{MO}(+)} / n_{\mathrm{M}(+)}=k_{2} n_{\mathrm{MO}} / k_{1} n_{\mathrm{M}}
$$

Substituting Eq. (1) for Eq. (4) and rearranging, we have

$$
\begin{aligned}
& n_{\mathrm{MO}(+)} Z_{\mathrm{O}}\left(m_{\mathrm{M}} m_{\mathrm{O}} / m_{\mathrm{MO}}\right)^{3 / 2} / n_{\mathrm{M}(+)} Z_{\mathrm{MO}} \\
& \quad=k_{2} n_{\mathrm{O}} \exp \left(E_{\mathrm{d}} / k T\right) / k_{1}\left(-2 \pi k T / h^{2}\right)^{3 / 2} .
\end{aligned}
$$

Assuming that the signal ratio $S_{\mathrm{MO}(+)} / S_{\mathrm{M}(+)}$ equals $n_{\mathrm{MO}(+)} / n_{\mathrm{M}(+)}$,

$$
\begin{aligned}
& \log \left[S_{\mathrm{MO}(+)} Z_{\mathrm{M}} Z_{\mathrm{O}}\left(m_{\mathrm{M}} m_{\mathrm{O}} / m_{\mathrm{MO}}\right)^{3 / 2} / S_{\mathrm{M}(+)} Z_{\mathrm{Mo}}\right] \\
& \quad=A+\log \left(k_{2} / k_{1}\right)+5040 E_{\mathrm{d}} / T
\end{aligned}
$$

where $A=\log \left[n_{\mathrm{o}} /\left(-2 \pi k / h^{2}\right)^{3 / 2}\right]$. Thus, if we can assume that $k_{2} / k_{1}$ is constant, the left-hand side of the Eq. (6), i.e., the logarithmic term in which the partition functions, atomic weights and molecular weights are taken into consideration, should have a linear relation with $E_{\mathrm{d}}$. Strictly speaking, the $k_{2} / k_{1}$ value varies with an element but, is general, $\log \left(k_{2} / k_{1}\right)$ is much smaller than $5040 E_{\mathrm{d}} / T$ because of the reason described below. For example, at a temperature of $5000 \mathrm{~K}$, the value of $\log \left(k_{2} / k_{1}\right)$ is approximately equal to the difference of the ionization potential of $\mathrm{M}\left(E_{\mathrm{i}(\mathrm{M}))}\right.$ and that of $\mathrm{MO}\left(E_{\mathrm{i}(\mathrm{MO})}\right)$ and the value of $5040 E_{\mathrm{d}} / T$ is nearly equal to $E_{\mathrm{d}}$. For most elements of which $E_{\mathrm{i}(\mathrm{MO})}$ values are given in the literature ${ }^{21}$, the difference $E_{\mathrm{i}(\mathrm{M})}-E_{\mathrm{i}(\mathrm{MO})}$ are smaller than 10 per cent of the $E_{\mathrm{d}}$ values. Typical exceptions are aluminum and silicon for which the differences exceed 70 and 39 per cent of the $E_{\mathrm{d}}$ values, respectively.

To obtain values of the left-hand side of Eq. (6), the partition functions of $\mathbf{M}$ and $\mathrm{O}$ were calculated from the data listed by de Galan et al. ${ }^{22}$ For molecules MO, electronic, vibrational and rotational levels must be included in the summation in the definition of the partition function. It generally suffices to consider only the lowest electronic level. ${ }^{23}$ However, the designation of this level is not always known with certainty. The spectroscopic data required for the calculation of $Z_{\mathrm{MO}}$ were taken from the literature ${ }^{24,25}$, but among the test elements shown in Fig. 6 the calculation was possible only for 8 elements ( $\mathrm{Zr}, \mathrm{La}, \mathrm{Y}, \mathrm{V}, \mathrm{Sn}, \mathrm{Ba}, \mathrm{Sr}, \mathrm{Sb})$ due to a lack of spectroscopic data. The experimental data of $S_{\mathrm{MO}(+)} / S_{\mathrm{M}(+)}$ used were the same as those used in Fig. 6. The results are plotted in Fig. 7 as a function of the dissociation energy. Clearly the slope is larger than that in Fig. 6; in other words, a lower temperature can be obtained from the slope in Fig. 7. The best fit of the data produces a temperature of $6650 \mathrm{~K}$. This is close to the ICP temperature. Thus, the remaining oxide levels in the ICP-MS spectra may partly reflect the oxide formation in ICP.

\section{Spectral interferences due to oxide ion signals}

In the ICP-MS analysis of real samples, equivalent concentration data are useful since they provide quantitative information concerning spectral interference. Equivalent concentration levels have been reported for background molecular ion interference ${ }^{3}$ as well as calcium, manganese and iron poly-atomic ion inter-

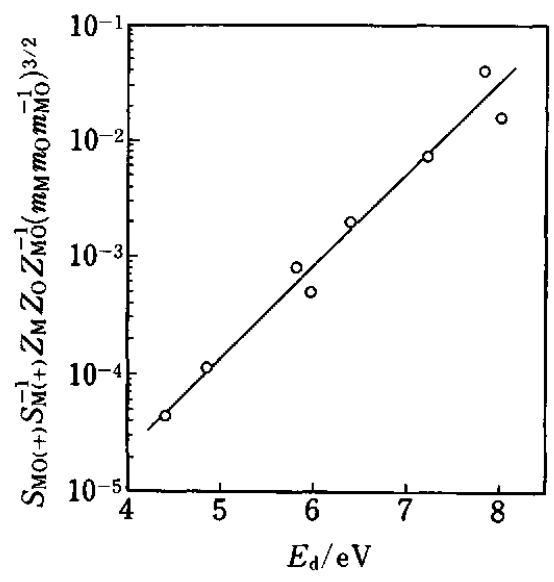

Fig. 7 Signal ratio in consideration of partition functions and atomic and molecular weights as a function of the oxide dissociation energy. 
Table 2 Equivalent concentration data $\left(\mathrm{ng} \mathrm{ml}^{-1}\right)$ for oxide ion interferences

\begin{tabular}{cccc}
\hline $\begin{array}{c}\text { Analyte } \\
\text { ion }\end{array}$ & $\begin{array}{c}\text { Relative } \\
\text { abundance }\end{array}$ & $\begin{array}{c}\text { Interfering } \\
\text { oxide }\end{array}$ & $\begin{array}{c}\text { Equivalent } \\
\text { concentration }\end{array}$ \\
\hline${ }^{27} \mathrm{Al}$ & 100 & BO & 0.47 \\
${ }^{63} \mathrm{Cu}$ & 69.1 & TiO & 12 \\
${ }^{64} \mathrm{Zn}$ & 48.9 & TiO & 10 \\
${ }^{106} \mathrm{Pd}$ & 27.3 & $\mathrm{ZrO}$ & 9.7 \\
${ }^{107} \mathrm{Ag}$ & 51.8 & $\mathrm{ZrO}$ & 1.3 \\
${ }^{158} \mathrm{Gd}$ & 24.7 & $\mathrm{NdO}$ & 7.8 \\
${ }^{159} \mathrm{~Tb}$ & 100 & $\mathrm{NdO}$ & 0.96 \\
${ }^{164} \mathrm{Dy}$ & 28.2 & $\mathrm{NdO}$ & 1.9 \\
${ }^{174} \mathrm{Yb}$ & 31.8 & GdO & 3.9 \\
${ }^{175} \mathrm{Lu}$ & 97.4 & $\mathrm{TbO}$ & 17 \\
${ }^{181} \mathrm{Ta}$ & 99.9 & $\mathrm{HoO}$ & 4.4 \\
${ }^{184} \mathrm{~W}$ & 30.7 & ErO & 4.9 \\
${ }^{197} \mathrm{Au}$ & 100 & TaO & 12 \\
\hline
\end{tabular}

a. Equivalent concentration is analyte concentration in $\mathrm{ng} \mathrm{ml}^{-1}$ to give equivalent signal to that of oxide ion of interfering element at $1 \mu \mathrm{g} \mathrm{ml}^{-1}$.

ference. ${ }^{26}$ From the experimental results shown in Figs. $1-3$, it is expected that the spectral interference due to oxide ions can be considerably reduced by an appropriate selection of operating conditions: typically, an $\mathrm{rf}$ power of $1.2 \mathrm{~kW}$, a carrier-gas flow rate of $0.91 \mathrm{~min}^{-1}$, and a sampling depth of $9 \mathrm{~mm}$. Under these conditions, the equivalent concentrations for oxide ion interference of analyte ions with interfering elements at $1 \mu \mathrm{g} \mathrm{ml}^{-1}$ were investigated. The results are shown in Table 2. Since the analyte ions selected are monoisotopes or have the largest abundance, the interference values given here are those which result in the most serious problem. With a few exceptions, it has been found that the oxide ion interference occurs at $0.1-1 \%$ levels of the interfering element concentration.

Information concerning oxide formation is quite important in view of any understanding of the spectral characteristics and interference in ICP-MS. The use of properly selected conditions could nearly minimize oxide formation. The temperature calculated from the relationship between the oxide fraction and the dissociation energy was close to the ICP temperature, but probably higher than the temperature of the supersonic expansion region after extraction from the plasma. This may indicate a state of non-equilibrium existing in the expansion stage if we consider that the oxide formation occurs during this stage. In order to strictly account for the origin of the oxide signals, further investigations are needed concerning phenomena during the sampling process, together with those in the plasma.

\section{References}

1. R. S. Houk, V. A. Fassel, G. D. Flesch, H. J. Svec, A. L. Gray and C. E. Taylor, Anal. Chem., 52, 2283 (1980).

2. A. R. Date and A. L. Gray, Spectrochim. Acta, 38B, 29 (1983).

3. A. L. Gray, Spectrochim. Acta, 40B, 1525 (1985).

4. D. J. Douglas and R. S. Houk, Prog. Analyt. Atom. Spectrosc., 8, 1 (1985).

5. R. S. Houk, Anal, Chem., 58, 97A (1986).

6. H. Kawaguchi, Anal. Sci., 4, 339 (1988).

7. G. M. Hieftje and G. H. Vickers, Anal. Chim. Acta, 216, 1 (1989).

8. M. A. Vaughan and G. Horlick, Appl. Spectrosc., 40, 434 (1986).

9. S. H. Tan and G. Horlick, Appl. Spectrosc., 40, 445 (1986).

10. G. Horlick, S. H. Tan, M. A. Vaugham and C. A. Rose, Spectrochim. Acta, 40B, 1555 (1985).

11. A. L. Gray, Spectrochim. Acta, 41B, 151 (1986).

12. H. P. Longerich, B. J. Fryer, D. F. Strong and C. J. Kantipuly, Spectrochim. Acta, 42B, 75 (1978).

13. H. Kawaguchi, T. Tanaka, T. Nakamura and A. Mizuike, Bunseki Kagaku, 36, 271 (1987).

14. G. Zhu and R. F. Browner, Appl. Spectrosc., 41, 349 (1987).

15. H. P. Longerich, B. J. Fryer and D. F. Strong, Spectrochim. Acta, 42B, 101 (1987).

16. D. J. Kalnicky, V. A. Fassel and R. N. Kniseley, Appl. Spectrosc., 31, 137 (1977).

17. D. J. Douglas and J. B. French, Spectrochim. Acta, 41B, 197 (1986).

18. A. L. Gray and J. G. Williams, J. Anal. At. Spectrom., 2, 81 (1987).

19. A. L. Gray and J. G. Williams, J. Anal. At. Spectrom., 2, 599 (1987).

20. V. I. Vedeneyev, L. V. Gurvich, V. A. Kondrat' yev, V. A. Medvedev and Ye. L. Frankevich, "Bond Energies: Ionization Potentials and Electron Affinities", Edward Arnold Ltd., London, 1966.

21. K. P. Huber and G. Herzberg, "Molecular Spectra and Molecular Structure IV: Constants of Diatomic Molecules", Van Nostrand Reinhold Co., New York, 1979.

22. L. de Galan, R. Smith and J. D. Winefordner, Spectrochim. Acta, 23B, 521 (1968).

23. P. W. J. M. Boumans, "Theory of Spectrochemical Excitation", p. 318, Hilger \& Watts, London, 1966.

24. G. Herzberg, "Molecular Spectra and Moecular Structure I: Spectra of Diatomic Molecules", 2nd ed., D. Van Nostrand Co., New Jersey, 1950.

25. S. N. Suchard ed., "Spectroscopic Data", Vol. 1, IFI/ Plenum, New York, 1975.

26. A. L. Date, Y. Y. Cheung and M. E. Stuart, Spectrochim. Acta, 42B, 3 (1987).

(Received July 20, 1989)

(Accepted September 8, 1989) 